\title{
A Database for Three Dioscoridean Illustrated Herbals
}

\author{
Anna Whipkey, Kirby Kalbaugh, Audra Franz, and Jules Janick ${ }^{\mathbf{1}}$ \\ Department of Horticulture and Landscape Architecture, Purdue University, \\ 625 Agriculture Mall Drive, Lafayette, IN 47907
}

Additional index words. Codex Neopolitanus, Juliana Anicia Codex, Morgan 652, Venn diagram

\begin{abstract}
An image database was developed for three illustrated recensions of the non-

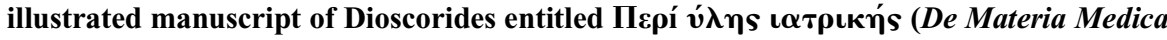
in Latin; On Medical Matters in English) written in approximately Year 65: Juliana Anicia Codex $(J A C)$ or Codex Vindobonensis produced in Year 512, Codex Neapolitanus (NAP) produced in the late sixth or early seventh century, and Morgan 652 (M652) produced between 927 and 985 . The database that brings up images and accompanying records is searchable by herbal, common name in English and Greek (Roman alphabet), binomial (current and in source document), and botanical family. In addition, a Venn diagram of images in the three herbals permits a search for images that are common or unique among the three herbals. The database makes it possible to locate images in herbals written in Greek that are difficult to access and will be useful to horticulturists and herbal scholars. The database can be accessed at <http://www.hort.purdue.edu/newcrop/herbalimages $>$.
\end{abstract}

The non-illustrated Greek herbal of Pedanius Dioscorides written in Year 65 is one of the most important and influential books on pharmacology, herbal medicine, and horticulture and influenced medicine for almost two millennia. The manuscript was reconstructed by Wellman (1906-14) in three volumes and recently translated into English (Beck, 2005). Three illustrated recensions in Greek still exist and are invaluable resources for studies of ancient and early medieval plant images. The earliest is the $J A C$, completed in Constantinople in 512 and dedicated to the Imperial Princess Juliana Anicia (462-527), daughter of Anicius Olybrius, Emperor of the western Roman Empire. The bound volume is located in the Österreichische in Vienna and is available in facsimile in two volumes (Der Wiener Dioskurides, 1998, 1999; Janick and Hummer, 2012). Identification of the two-volume $J A C$ images (folios 12v-387r) by the facsimile editor Otto Mazal was available in an index called Das Herbarium divided in two volumes that included binomials and families in Latin and common names and some descriptions in German.

The illustrated $N A P$ dates to $\approx 600$ and since 1923 resides in the Biblioteca Nazionale, Naples (Collins, 2000). A facsimile is available (Dioscurides De Materia Medica, Codex Neapolitanus Graceus I of the National Library of Naples, 2000). The NAP images have the Greek name as an integral part of most images, and there is an index of Greek names on p. 223 to 243 in the volume accompanying the facsimile. NAP appears to be an extended

Received for publication 6 Feb. 2014. Accepted for publication 29 May 2014

${ }^{1}$ To whom reprint requests should be addressed; e-mail janick@purdue.edu. version of $J A C$ with many images either copied from or based on $J A C$ and can be considered a sister manuscript based on a lost archetype, although it cannot be excluded that some images of $N A P$ were copied from $J A C$ (Janick and Stolarczyk, 2012).

M652 completed in Constantinople between 927 and 985 is related both to $J A C$ and $N A P$ (Janick et al., 2013). It is now in the collection of the Morgan Museum and Library where it is available online ( $<\mathrm{http}$ :// www.themorgan.org/home.asp $>$ ). An index has been made available by the library and contains the Greek name in Roman letters, common name, and binomial.

These three illustrated herbals are clearly related to each other either by copying or from an earlier lost manuscript. An image analysis of the three herbals was made by Janick et al. (2013) and in the process, a database was constructed to determine the relationship between images. The database is currently online $(<\mathrm{http}: / /$ www.hort.purdue.edu/newcrop/ herbalimages $>$ ). The objective of this article is to describe the construction of the database and bring it to the attention of horticulturists and herbal scholars who should find the information useful.

\section{Materials and Methods}

Acquisition and digitization of images. A database of the images contained in $J A C$ (404 images), NAP (410 images), and M652 (453 images) was constructed to make the visual and textual comparison of images a more manageable task. Facsimiles of $J A C$ and $N A P$ were scanned to create digitized images, whereas M652 was accessed from a digital online version available from the Morgan Museum and Library. The binomials, common English and Greek names of M652, were obtained from the Excel (Microsoft Inc., Redmond, WA) spreadsheet provided by The Morgan Library and Museum. Binomials and Greek names from $J A C$ associated with the $J A C$ images were based on the index made by Otto Mazel, the facsimile editor. The NAP images contained Greek names in red unicial and were also available in an index in the Greek alphabet provided in the accompanying volume of the facsimiles, which were put into Roman letters.

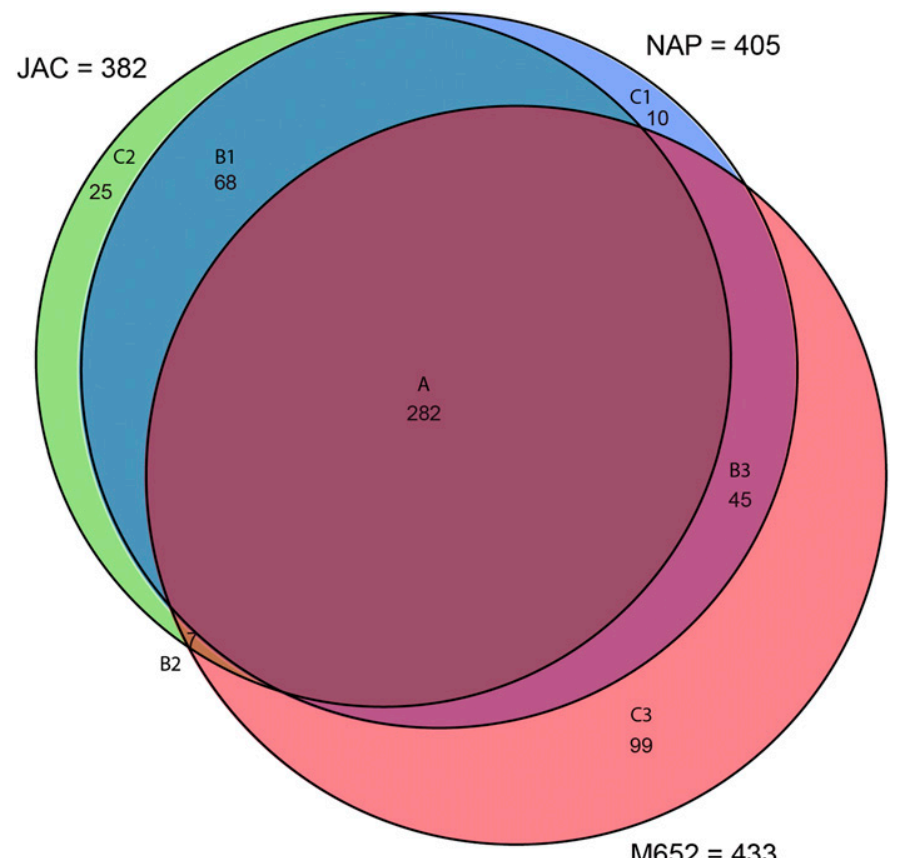

Fig. 1. Venn diagram of images in Juliana Anicia Codex (JAC), Codex Neapolitanus (NAP), and Morgan 652 (M652). Source: Janick et al. (2013). 
Database development. A relational database was built using FileMaker Pro 11.0 FileMaker Inc. A separate file was created for each herbal. Each image is a separate record containing the following fields: location in the source document by folio number and position on the page; Greek name (Roman alphabet); English common names; binomial in the source document, current binomial, and authority; botanical family; comment; and set number. The set number was the key field used to associate the matching images.

To make the database available online, the FileMaker database was exported to two-comma separated files. The first exported file contained the individual image records, which were used to create an image record table. The second exported file contained derived images called synteny groups (Janick et al., 2013), which were used to create a synteny set table. The exported data files were then imported into a MySQL Version: 5.5.13 (current database manufacturer Oracle Corporation).

Development of web interface. PHP scripting enables access to the database through a web interface. An index was made for each name field and the set field and all the information were made available in dropdown boxes for searching purposes. There were complications resulting from variant spelling, superimposition of more than one image in a few cases, and obvious errors in assigning proper names. These were corrected as they became obvious. All images and information are displayed together. Images can be enlarged by clicking on them. In addition, it is possible to search any field such as current binomial, source binomial, family, common name, Greek name, folio, or comments without recourse to the dropdown menu. Results however are not restricted to whole words only. Thus, putting in oat will also come up with goat.

We have also reproduced the Venn diagram (Fig. 1) from Janick et al. (2013). Clicking on the labels in the diagram on the Herbal Images web site will retrieve common images from each comparison, e.g., A will bring up images common to $J A C, N A P$, and M652. It should be noted that this Venn diagram is based on 382 images for $J A C$, 405 images for $N A P$, and 433 images for M652. In the case of M652, the reduced number is because we included only images from folios 3 to 199 (Book, 1, Fruits and Herbs of Dioscorides); in the case of $J A C$, only images from folio $12 \mathrm{v}$ to 387 (based on Dioscorides) were included and images made in the 12 th to 13 th century were omitted; and in the case of $N A P$, only images were included, although records were available from some torn pages.

\section{Using the Database}

An example of how the database operates can be explained as follows. Let us assume the viewer is interested in carrot. A number of terms might be used including carrot, wild carrot, cultivated carrot, Daucus, Daucus carota, or Daucus gingidium. Using Daucus

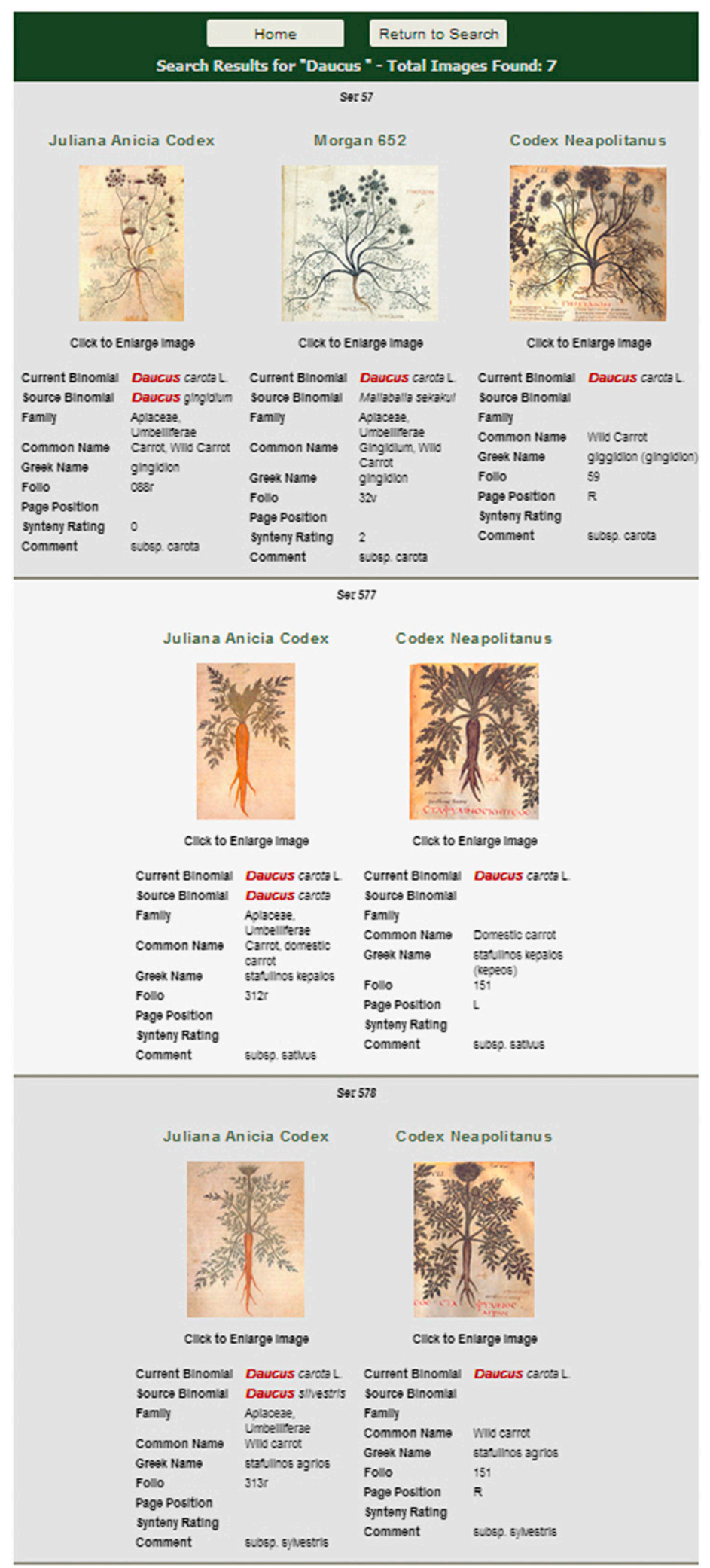

Fig. 2. Results returned when entering Daucus in "Search by Word or Phrase."

as a search term in "Search by Word or Phrase" will bring up seven images as shown in Figure 2. These will include Daucus carota, Daucus gingidium, Mallabaila sekakul, and Daucus silvestris, but the information will make clear that Daucus carota is the current binomial for all. However, it will become obvious that both Daucus carota include wild carrot (Daucus carota L. subsp. sylvestris) and cultivated carrot (Daucus carota L. subsp. carota). These terms can also be accessed using the dropdown index. It should be noted that if we search for the term carrot, we also come up with Thapsia garganica (known 
variously as false fennel and deadly carrot) because the word carrot occurs in the common name field.

\section{Conclusions}

The database has a number of valuable uses. First it makes available images from herbals that are difficult to access. Second, it allows images to be searched by common name, binomials, or Greek names in the Roman alphabet. Third it shows which images are unique to one herbal, common to two of the three herbals, or common to all three of the herbals. The database is considered a work in progress, and we plan to incorporate corrections and additions as they are supplied as well as providing updated binomials. Plant taxonomists are invited to submit nomenclature corrections using a feedback form.

\section{Literature Cited}

Beck, L.Y. (ed.). 2005. Pedanius Diocorides of Anazarbus. De Material Medica OlmsWeidmann, Hildesheim, Germany.

Collins, M. 2000. Medieval herbals. The illustrative traditions. The British Library, London.

Der Wiener Dioskurides. 1998, 1999. 2 vol (commentary by Otto Mazal). Akademische Drucku, Verlagsanstalt, Graz, Austria.

Dioscurides De Materia Medica, Codex Neapolitnus Graecus I of the National Library of Naples (facsimile). 2000 (undated). MIAHTOS, Alilmos, Greece.
Janick, J. and K.E. Hummer. 2012. The 1500th anniversary (512-2012) of the Juliania Anicia Codex: An illustrated Dioscoridean recension. Chron. Hort. 52:9-15.

Janick, J. and J. Stolarczyk. 2012. Ancient Greek illustrated Dioscoridean herbals: Origins and impact of the Juliana Anicia Codex and the Codex Neopolitanus. Not. Bot. Hort. Agrobo 40:9-17. 30 June 2014. <http://www.notulaebotanicae.ro> $(1842-4309)$

Janick, J., A.L. Whipkey, and J. Stolarczyk. 2013. Synteny of images in three illustrated Dioscoridean Herbals: Juliana Anicia Codex, Codex Neapolitanus, and Morgan 652. Not. Bot. Hort. Agrobo 40:9-17.

Wellman, M. 1906-14. Pedanii Diocuridis Anazarbei De Material Medica Libri Quinque. 3 vol., reprinted 1958. Weidmann, Berlin, Germany. 